\title{
EVOLUÇÃO DAS PRÁTICAS DE INOVAÇÃO ABERTA NA INDÚSTRIA ALIMENTÍCIA: O CASO DE UMA EMPRESA BRASILEIRA
}

Juliana Braga de Carvalho (julianac92@gmail.com) - Universidade Federal de Minas Gerais.

Júlio Cézar Fonseca de Melo (juliocfmelo@gmail.com) - Universidade Federal de Minas Gerais.

Raoni Barros Bagno (rbagno@dep.ufmg.br) - Universidade Federal de Minas Gerais.

\begin{abstract}
RESUMO
Mudanças na demanda atual de alimentos (e.g. produtos customizados e interesses ligados à saúde), o surgimento de alimentos mais complexos e o envolvimento de diversos agentes têm motivado a incorporação de práticas de inovação aberta nas empresas do setor alimentício brasileiro. O presente estudo teve como principal objetivo avaliar a evolução no uso dessas práticas no contexto da indústria alimentícia brasileira. Este estudo de caso de natureza qualitativa foi realizado a partir de entrevistas semiestruturadas em profundidade, com quatro funcionários do departamento de inovação de uma grande empresa fabricante de alimentos cárneos (aves e suinos) e processados diversos. Dentre os principais resultados encontrados, pontua-se: o grau de disseminação do conceito de inovação aberta no ambiente interno da empresa; o perfil das iniciativas desenvolvidas com diferentes agentes (e.g. fornecedores, clientes, Instituto de Ciência e Tecnologia (ICTs), empresas intermediadoras, concorrentes, startups); a evolução das práticas ao longo do tempo (i.e. as que foram enfraquecidas ou fortaleceram-se); e a possibilidade de conexões com novos agentes, até então não exploradas. Este trabalho contribui para a teoria de gestão da inovação pela avaliação de práticas de inovação aberta em um contexto relevante e pouco explorado pela literatura. Finalmente, o trabalho reforça a perspectiva do uso de conceitos de inovação aberta como alavancas da capacidade de inovação das empresas da indústria a perspectiva do uso de práticas de inovação aberta como instrumento potencializador da capacidade inovadora das empresas da indústria alimentícia.
\end{abstract}

Palavras-chave: Gestão da Inovação; Inovação Aberta; Indústria Alimentícia.

Área: Gestão do Processo de Desenvolvimento de Produtos

\section{INTRODUÇÃO}

O Brasil, nas últimas décadas, tem sido referência como um dos países estratégicos na produção de alimentos no mundo (EMBRAPA, 2014). Segundo dados da revista FoodDrink Europe (2014), o Brasil está entre os quatro países mais exportadores de alimentos e bebidas, com representação de aproximadamente $7,5 \%$ do mercado internacional. Além da boa reputação no exterior, o setor de alimentos no Brasil apresenta grande importância nacional. Segundo dados da ABIA (Associação Brasileira das Indústria de Alimentação), o setor é o segmento industrial com a maior geração de empregos diretos no país e representou, em 2013, aproximadamente $23 \%$ do PIB.

Historicamente um setor mais conservador, a indústria de alimentos, em comparação à outras indústrias, apresenta-se mais fechada no que se refere à gestão de suas inovações (BIGLIARDI; GALATI, 2013; ARCESE et al., 2015). No entanto, mudanças na demanda atual de alimentos e a complexa cadeia de agentes, que envolvem a indústria, têm motivado o 
desenvolvimento de estratégias inovadoras nas organizações desse setor. $O$ mercado globalizado e os clientes mais exigentes, com suas necessidades pessoais, estão influenciando as empresas a adotarem uma conduta mais ágil, flexível e aberta (BIGLIARDI; GALATI, 2013; ARCESE et al., 2015). Dessa maneira, práticas de inovação aberta tornam-se essenciais para o crescimento das organizações e da indústria de alimentos.

As oportunidades de crescimento para pequenas empresas promissoras de base tecnológica, chamadas startups, a maior mobilidade de trabalhadores devido a globalização, além de um mercado mais ágil e flexível são fatores que tornaram o ambiente mais competitivo para o desenvolvimento de inovações (CHESBROUGH, 2003; HUIZINGH, 2011). Dessa maneira, as empresas, anteriormente com processos conservadores e fechados, com intuito de se renovarem no mercado e aumentar sua vantagem competitiva, passam a buscar uma mudança na maneira de gerar ideias e comercializá-las.

O conceito de inovação aberta proposto por Chesbrough (2003) sugere uma fronteira menos rígida entre a organização e ambiente externo durante o processo de desenvolvimento de inovações, de forma que haja interações colaborativas entre os atores neste processo. $\mathrm{O}$ presente estudo teve como principal objetivo avaliar a evolução no uso das práticas de inovação aberta no contexto da indústria alimentícia brasileira. Para isso, um estudo de caso de natureza qualitativa foi conduzido em uma das maiores organizações brasileiras fabricante de produtos cárneos (aves e suínos) e processados diversos.

\section{REVISÃO BIBLIOGRÁFICA}

O termo "Inovação Aberta" (Open Innovation, em inglês) foi introduzido por Chesbrough (2003) e sugere uma fronteira menos rígida entre a organização e o ambiente externo, de forma que ambos sejam beneficiados com o surgimento de inovações. Ideias externas podem ser importadas para alavancar o desenvolvimento interno e assim ampliar as operações, da mesma maneira que ideias surgidas internamente, com potencial em outros contextos, podem ser compartilhadas além de suas fronteiras. O fluxo de entrada de conhecimento na organização é denominado inbound e o fluxo de saída, denominado outbound (HUIZINGH, 2011).

Docherty (2006) apresentou um modelo que incorpora os principais conceitos de processo de inovação à abordagem de inovação aberta proposta por Chesbrough (2003). A Figura 1 ilustra o modelo de Docherty (2006), em que as empresas desenvolvem um olhar de dentro para fora, e vice-versa, ao longo dos três estágios: iniciação difusa (Fuzzy Front-End), desenvolvimento e comercialização. Segundo o autor, essa maneira de enxergar a inovação agrega mais valor ao longo do processo.

Figura 1. Modelo de funil de inovação aberta. Fonte: Adaptada de Docherty (2006)

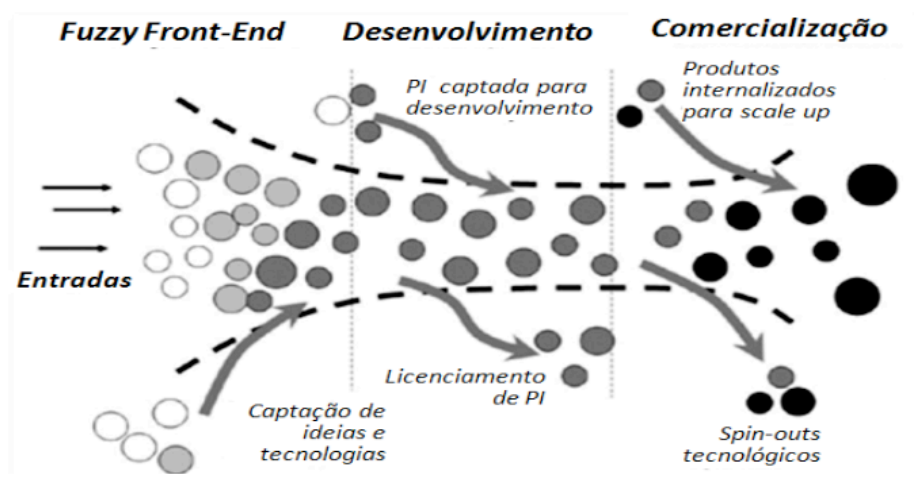


No contexto do setor alimentício, o desenvolvimento de inovações apresenta histórico com mudanças sobretudo incrementais (ARCESE et al., 2015). Dessa forma, o setor é considerado conservador e com poucos avanços tecnológicos introduzidos no mercado (BIGLIARDI; GALATI, 2013). Ambiente de intensa competição, a indústria alimentícia é caracterizada por desenvolver produtos com reduzidos ciclos de vida, para atender uma grande variedade de consumidores com demandas diferentes e exigência por altos padrões de qualidade (ARCESE et al., 2015).

Segundo Bigliardi e Galati (2013), mudanças na demanda atual de alimentos (e.g. produtos customizados e interesses ligados à saúde), o surgimento de alimentos mais complexos, e o envolvimento de diversos agentes têm motivado a incorporação de práticas de inovação aberta nas empresas desse setor. Para desenvolver produtos alimentícios que atendam clientes mais exigentes e em maior quantidade, é necessário importar conhecimento externo à organização.

O modelo proposto por Bigliardi e Galati (2013), apresentado na Figura 2, evidencia o processo de inovação aberta na indústria alimentícia. As setas indicam os fluxos de conhecimento entre os diferentes atores dentro e fora da cadeia de suprimentos.

Figura 2. Modelo de inovação aberta no setor alimentício. Fonte: Adaptada de Bigliardi e Galati (2013)

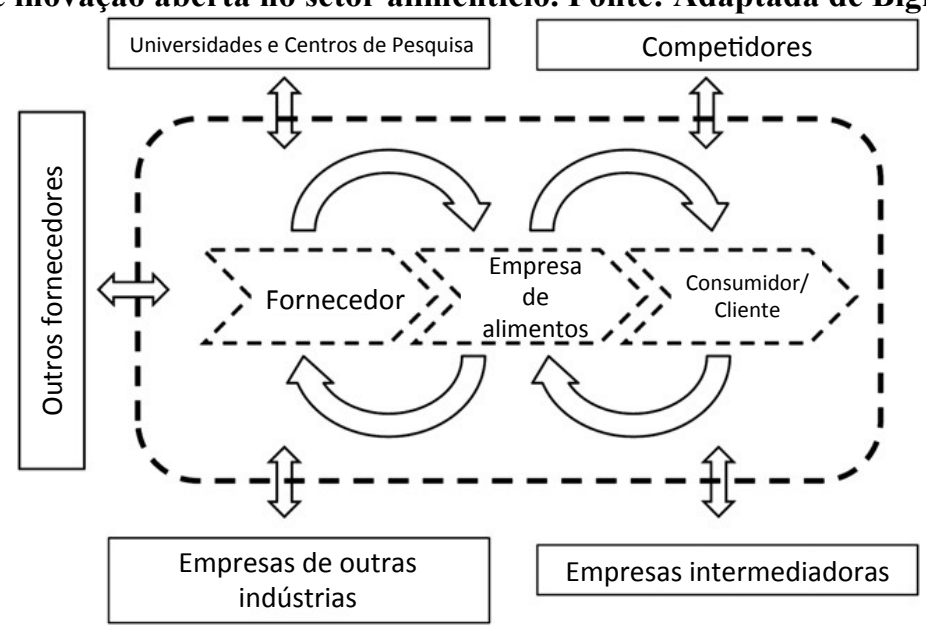

Os principais agentes externos que estão presentes em práticas de inovação aberta nas organizações são: (i) Institutos de Ciência e Tecnologia (ICTs), (ii) fornecedores, (iii) clientes, (iv) concorrentes, (v) startups e (vi) empresas intermediadoras.

Primeiramente, os ICTs podem ser fonte de patentes embrionárias para serem investidas em desenvolvimento nas empresas (NAMBISAN; SAWHNEY, 2007). Em relação aos fornecedores, as organizações têm possibilidade de desenvolver novas ideias em conjunto, com intuito de facilitar a comunicação e corresponder melhor as necessidades do projeto (BIGLIARDI; GALATI, 2013). Principalmente durante a ideação e o desenvolvimento, as empresas buscam captar as necessidades dos clientes para diminuir incertezas de seus produtos (LANCKER et al., 2016). Por outro lado, competidores podem importar ideias, tecnologias ou produtos que seriam descartados pela empresa (CHESBROUGH, 2003). Parcerias com startups proporcionam busca por soluções de problemas e potenciais ideias, além da importação de tecnologias e inovações disruptivas (HUIZINGH, 2011). Por fim, empresas intermediadoras têm papel de corretores, ao auxiliar as organizações na busca por projetos potenciais de inovação e também na exportação de projetos que seriam descartados 
(NAMBISAN; SAWHNEY, 2007) texto será utilizado para a compilação dos anais do evento, portanto ele deve constar todas as informações do artigo, incluindo autores.

\section{METODOLOGIA}

O presente estudo de caso é de natureza qualitativa e foi realizado em uma das maiores organizações brasileiras fabricantes de alimentos cárneos (aves e suínos) e processados diversos. A empresa atua globalmente e seus clientes diretos são varejistas e atacadistas, além de empresas do setor de food service (restaurantes e redes de fast-food). O seu portfólio é composto por mais de 30 marcas e os produtos são comercializados em mais de 150 países. As operações estão distribuídas em 54 plantas produtivas além de escritórios e centros de distribuição localizados em sete países. A partir das atividades de aproximadamente 100 mil funcionários, a organização faturou 33 bilhões de reais em 2016.

A organização estudada projeta e desenvolve inovações por meio de um setor interno dedicado, a "Área de Inovação", que possui, atualmente, 25 colaboradores divididos em três principais frentes de trabalho: (i) Inteligência de Clientes e Mercado (CMI); (ii) Categorias; e (iii) Novos Mercados. A primeira desenvolve pesquisas para entender as tendências de mercado e do consumidor. A frente de categorias abrange os responsáveis pelos projetos de inovação divididos entre as principais categorias de produtos que a empresa trabalha (in natura, margarinas, embutidos, frios, food service e comemorativos). E, por último, a frente de novos mercados trabalha com projetos mais disruptivos e não se encaixam em uma categoria específica, como a entrada em novos mercados que a empresa não atuava anteriormente.

Em busca do principal objetivo do trabalho, entrevistas semiestruturadas em profundidade foram conduzidas com quatro funcionários do departamento de inovação da empresa e que participam ativamente de projetos com práticas de inovação aberta. A Figura 3 apresenta um quadro com as informações de cada colaborador entrevistado.

Figura 3. Informações dos entrevistados. Fonte: Elaborado pelos autores

\begin{tabular}{|c|l|c|c|}
\cline { 2 - 4 } \multicolumn{1}{c|}{ Cargo } & $\begin{array}{c}\text { Tempo de } \\
\text { empresa }\end{array}$ & $\begin{array}{c}\text { Experiência no setor de } \\
\text { inovação }\end{array}$ \\
\hline $\mathbf{1}$ & $\begin{array}{l}\text { Gerente de Inovação - Categorias } \\
\text { (Embutidos, In Natura, } \\
\text { Comemorativos e Food Service) }\end{array}$ & 4,5 anos & $\begin{array}{c}2,3 \text { anos - Participou do momento de } \\
\text { expansão do setor na empresa }\end{array}$ \\
\hline $\mathbf{2}$ & $\begin{array}{l}\text { Especialista de Inovação - } \\
\text { Categorias (Congelados) }\end{array}$ & 4,5 anos & $\begin{array}{c}2,3 \text { anos - A partir de um projeto } \\
\text { ligado a sustentabilidade }\end{array}$ \\
\hline $\mathbf{3}$ & $\begin{array}{l}\text { Gerente de Inovação - Categorias } \\
\text { (Frios e Margarinas) e responsável } \\
\text { pelo projeto com startups }\end{array}$ & 1,5 anos & $\begin{array}{c}\text { 9 anos - Experiência anterior em outra } \\
\text { empresa }\end{array}$ \\
\hline $\mathbf{4}$ & $\begin{array}{l}\text { Gerente Executivo de Inovação - } \\
\text { Categorias (Embutidos, In Natura, } \\
\text { Comemorativos e Food Service) }\end{array}$ & 11 anos & $\begin{array}{l}1 \text { mês no setor mas com experiência } \\
\text { anterior no marketing com projetos } \\
\text { de inovação }\end{array}$ \\
\hline
\end{tabular}

As entrevistas foram conduzidas por meio de um roteiro com perguntas abertas, focado em diferentes pontos do tempo (i.e. passado, presente e futuro), ou seja, para entender quais práticas de inovação estão presentes no contexto da empresa, quais eram realizadas anteriormente e perderam força ou evoluíram e quais futuras práticas eram esperadas. Os relatos foram gravados e integralmente transcritos, o que permitiu maior rigor e integralidade na coleta de dados e assim a análise pôde ser minuciosa. Os dados foram analisados por meio de comparação entre as entrevistas e a busca de percepções (insights) e definição de padrões 
entre elas. A partir dessas análises, buscou-se entender "por quê" relações emergentes ocorrem e assim houve comparação do caso estudado com a literatura.

\section{DISCUSSÃO DOS RESULTADOS}

De maneira geral, o conceito de inovação aberta apresentou considerável disseminação entre os entrevistados. As práticas estão presentes ao longo de todo o processo de desenvolvimento (i.e. das novas ideias aos produtos), como também fazem parte da estratégia de inovação da empresa estudada como declarado ao longo das entrevistas.

Os entrevistados destacaram a evolução da mentalidade da organização, para um momento em que o desenvolvimento de inovação aberta é essencial para crescer e ter vantagem competitiva. Segundo um dos entrevistados, a empresa tinha uma visão muito protecionista e fechada, com segredo industrial ao desenvolver as próprias tecnologias e não compartilhar com outros agentes. Para colocar as ideias em prática, muitas vezes é necessário um knowhow (conhecimento aplicado) que a organização não detém. Outro entrevistado afirmou que a evolução do consumidor, com a criação de necessidades diferentes, indica que o negócio precisa se reinventar. Em uma de suas falas, ele evidencia: "a gente não vai sobreviver mais cinco anos, com o mesmo portfólio de produtos que a gente tem, com o consumidor que está vindo". Segundo esse entrevistado, a empresa continua progredindo com essa nova mentalidade de construir suas soluções em conjunto com consumidores e outros atores, além de permitir experimentar, efetivar e errar mais em pequena escala.

As práticas de inovação aberta na organização em estudo foram definidas em duas principais frentes, de acordo com um dos entrevistados: (i) focada na cadeia; e (ii) focada no consumidor. A primeira envolve parcerias para melhorar alguma deficiência da empresa, quando há falta de conhecimento ou de tecnologia. Essas parcerias estão mais ligadas ao meio científico e são realizadas com universidades, instituições e centros de pesquisa. Por outro lado, a frente focada no consumidor, segundo o entrevistado, está mais ligada ao comercial e ao marketing. Ele aponta que "tudo, no final, vai ter um impacto para o consumidor", mas essa segunda frente envolve parcerias que estariam diretamente ligadas ao cliente final.

Outro ponto, também identificado nas entrevistas, é a burocracia na realização de projetos com práticas de inovação aberta. Segundo um dos entrevistados, ainda existem entraves consideráveis para parcerias com empresas que teriam tecnologia necessária para desenvolvimento de um produto. Ele destaca que essas parcerias poderiam acontecer com maior frequência do que de fato acontecem, se não demorasse tanto tempo para aprovação interna. Um segundo entrevistado apontou que demandas vindas do setor de marketing costumam ter maior prioridade em aprovação de projetos. Ao lançar um novo produto, existe uma estratégia por detrás e se isso está muito amarrado à uma necessidade do marketing, $\mathrm{o}$ entrevistado ressalta que "tudo flui por causa disso". Ficou evidente ao longo das entrevistas a influência desse setor na seleção de projetos.

Por meio de exemplos de projetos relatados ao longo das entrevistas, foi possível identificar, para cada agente externo verificado na literatura, as fases do processo de inovação em que as relações de cooperação são mais fortes.

\section{Institutos de Ciência e Tecnologia (ICTS)}

A empresa desenvolveu parcerias com universidades e centros de pesquisa ao buscar ideias para novos de produtos, codesenvolver soluções inovadoras e investir em linhas e plataformas tecnológicas. Essas relações eram criadas tanto para solucionar problemas tecnológicos com o $\mathrm{P} \& \mathrm{D}$, quanto para problemas de design de produto com o marketing. No entanto, essas 
relações perderam força nos últimos tempos, segundo os entrevistados, principalmente por: o imediatismo do negócio; a saída de uma pessoa responsável pelo gerenciamento desses contatos e o crescimento de parcerias com startups.

\section{Fornecedores}

As parcerias com os fornecedores no desenvolvimento de inovações ocorrem desde a criação do setor. Uma das entrevistas destacou que a relação com fornecedores gera benchmarking sobre o que está dando certo e errado em outros contextos empresariais. A tendência vivenciada na organização tem sido de inclui-los a partir do momento zero, para codesenvolver as soluções. Ocorrem também parcerias em que o fornecedor proporciona alguma tecnologia necessária, para um processo que a empresa estudada não possui e seria muito caro investir internamente. Os fornecedores participam ainda de sessões de inovação promovidas pela empresa, em que apresentam soluções inovadoras a partir de uma demanda da empresa estudada.

\section{Clientes e consumidores finais}

A organização não fornece diretamente aos consumidores finais, mas possui práticas para desenvolvimento de inovação com esses agentes. Assim como no caso dos fornecedores, a empresa promove sessões de inovação com o consumidor, em que pessoas de algum segmento específico são selecionadas para participar e opinar sobre o conceito de um produto e assim gerar novas ideias. Segundo um dos entrevistados, a empresa ainda não aproveita o máximo que poderia de seus consumidores, uma vez que não abre espaço para eles ajudarem desde o início na construção da ideia. A relação com esses agentes é mais voltada para validação sobre o novo produto ao longo do projeto e apresenta-se mais forte durante a ideação e o desenvolvimento. Por outro lado, a empresa estudada está codesenvolvendo uma solução com um de seus clientes supermercadistas, que possuem tecnologia e know-how para criar um novo modelo de negócios.

\section{Concorrentes}

As entrevistas revelaram que a relação da empresa com competidores é de bastante rivalidade e por isso, dificilmente haveria alguma parceria para projetos em breve.

\section{Startups}

A interação com esses agentes teve início há aproximadamente um ano e hoje conta com um responsável dedicado que desenvolve estudos para entender melhor o mercado. Os entrevistados destacaram que, diferentemente de universidades e centros de pesquisa, as startups apresentam soluções mais desenvolvidas para o negócio e voltadas para o mercado e assim facilitam a parceria com a empresa. Atualmente, uma das práticas realizadas com startups é focada em reduzir custos no chão de fábrica por meio de novas tecnologias. A relação com esses agentes proporciona ganho mútuo ao longo de todo processo de inovação. Pelo lado da empresa, os custos de P\&D são muito altos e o obstáculo de reinventar-se sozinha é bastante significativo; pelo lado da startup, trabalhar com um cliente de grande porte e bem estabelecido no mercado é uma ótima oportunidade de alavancagem rápida de seu negócio.

\section{Empresas intermediadoras}

A organização estudada desenvolve parcerias com empresas intermediadoras, que são especialistas em determinadas áreas e colaboram para as etapas de ideação e comercialização. Pesquisas de mercado, qualitativas e quantitativas, e pesquisas de tendências são realizadas por empresas parceiras. Na etapa de comercialização, agências de trade marketing, com 
expertise nos pontos de venda, são contratadas para proporem soluções inovadoras sobre a exposição dos produtos.

\section{Empresas de base tecnológica}

A interação com empresas tecnológicas destacada durante as entrevistas não foi abordada na revisão bibliográfica. A empresa estudada busca parcerias com organizações menores que possuem tecnologia necessária para alguma parte do processo produtivo. Essas relações ocorrem em projetos mais disruptivos, quando não há recursos tecnológicos ou conhecimento aplicado fundamentais para seu desenvolvimento e o investimento seria muito elevado.

As práticas de inovação aberta identificadas na entrevista estão evidenciadas na imagem do Anexo, em que as interações com os agentes externos são alocadas em cada etapa do processo. Os fluxos das interações também são identificados na imagem, assim como denominado por Huizingh (2011).

As intensidade das interações da empresa em cada etapa do processo de inovação aberta com os agentes externos são demonstradas pela Figura 4. A partir das citações de exemplos de práticas ao longo das entrevistas, a Figura 4 foi elaborada em que as cores mais fortes indicam práticas mais abordadas. Dessa forma, verificou-se que na etapa de ideação os ICTs apresentam maior relevância de contribuição com a empresa estudada; no desenvolvimento os agentes mais citados foram ICTs e startups; e na comercialização os agentes mais relevantes foram startups. As fases do processo de inovação aberta com maior número de contribuições externas são ideação e desenvolvimento com pesos iguais. $\mathrm{O}$ ator externo mais citado foram as startups, o que demonstra a importância do projeto realizado com esses agentes.

Figura 4. Intensidade das interações por quadrante. Fonte: Elaborado pelos autores

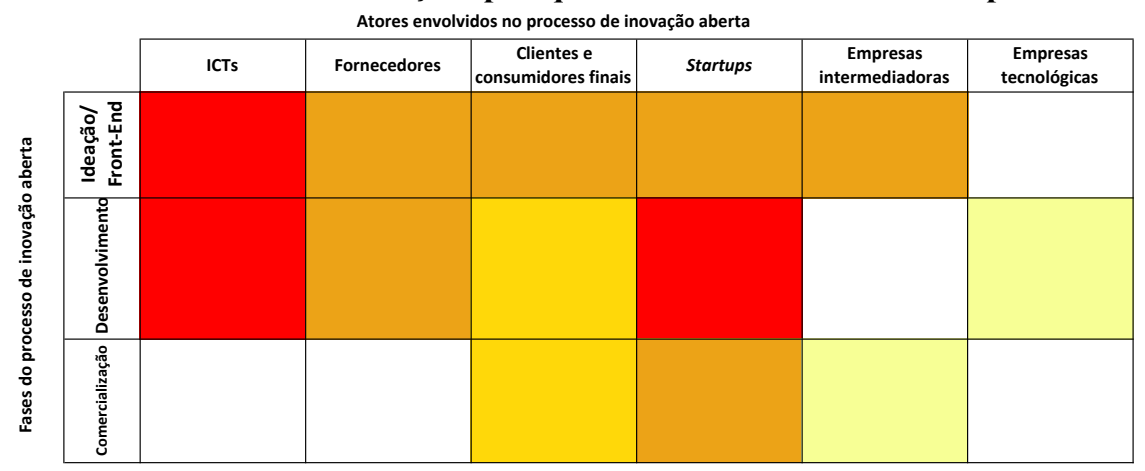

As entrevistas também revelaram que algumas práticas de inovação aberta têm evoluído entre agentes. Figura 5 ilustra essa evolução que ocorre entre os atores externos mais mencionados (Figura 4). Segundo os entrevistados, as interações com ICTs têm perdido força na organização. O principal motivo indicado foi o imediatismo do negócio, uma vez que a necessidade de colocar produtos rápidos no mercado muitas vezes não resiste à investimentos de longo prazo com as universidades e centros de pesquisa. Segundo um dos entrevistados, a empresa que investia em plataformas tecnológicas, com muita pesquisa durante dois a três anos em universidades, agora busca um conhecimento já aplicado no mercado. Esse entrevistado ressalta a migração da relação empresa-universidades para empresa-startups. A empresa apresenta um projeto dedicado para parcerias com startups e possui um canal aberto online de comunicação com esses agentes. A busca por parcerias com universidades continua, mas agora focada naquelas que possuem uma incubadora ou aceleradora. $\mathrm{O}$ projeto de 
interação com startups está em expansão na empresa e foi citado por todos os entrevistados como iniciativa de alto potencial para o desenvolvimento de inovações.

Figura 5. Evolução das práticas de inovação aberta na empresa estudada. Fonte: Elaborado pelos autores

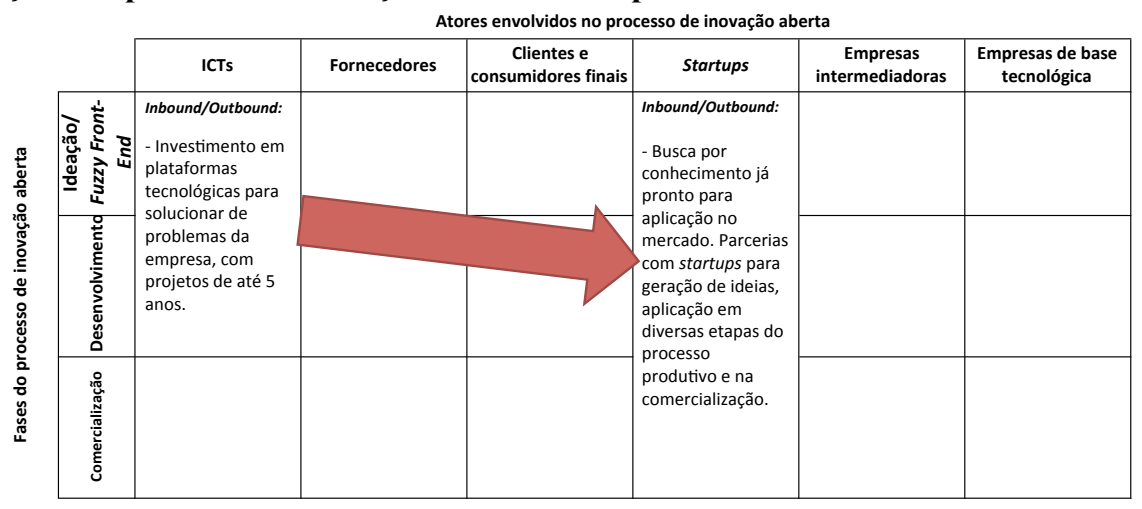

Além das práticas de inovação aberta em projetos atuais e recentes, outras relações com agentes externos foram destacadas como potenciais no futuro da empresa. Por ser uma organização internacional, um dos entrevistados abordou que relações com empresas estrangeiras poderiam ser mais exploradas para aumentar o alcance das inovações. O projeto com startups é bastante recente, então foi citado por alguns entrevistados como potencial para o futuro da organização. Outra prática abordada foi expandir parcerias para projetos piloto, em que possíveis erros ocorrem em menor escala e assim o desenvolvimento de inovação torna-se mais frequente.

\section{CONCLUSÃO}

O presente estudo apresentou as práticas de inovação aberta relacionadas na literatura e, a partir disso, identificou como a indústria alimentícia brasileira aborda essas relações, com diferentes agentes externos, ao longo das etapas do processo. Os resultados apontaram o grau de disseminação do conceito de inovação aberta no ambiente interno da empresa; o perfil das iniciativas desenvolvidas com diferentes agentes (e.g. Instituto de Ciência e Tecnologia (ICTs), fornecedores, clientes, concorrentes, startups, empresas intermediadoras, empresas tecnológicas); a evolução das práticas ao longo do tempo (i.e. as que foram enfraquecidas ou fortaleceram-se); e a possibilidade de conexões com novos agentes, até então não exploradas.

Por ser um contexto extremamente relevante e pouco explorado pela literatura, o presente estudo contribui significativamente para a teoria da gestão da inovação pela avaliação de práticas de inovação aberta. Dessa maneira, o trabalho reforça a perspectiva do uso de práticas de inovação aberta como instrumento potencializador da capacidade inovadora das empresas da indústria alimentícia.

No entanto, o estudo apresenta duas principais limitações que devem ser consideradas: (i) a visão única de uma grande organização brasileira do setor alimentício; e (ii) as entrevistas conduzidas apenas com colaboradores internos da área de inovação. Para retratar o cenário brasileiro mais profundamente, um próximo trabalho deveria abranger um maior número de organizações e de diferentes tipos da indústria alimentícia. Além disso, as entrevistas poderiam ser realizadas com alguns dos agentes externos para entender as contribuições reais da estratégia de inovação aberta em outra perspectiva. 


\section{REFERÊNCIAS}

ARCESE, G. et al. Evidence and Experience of Open Sustainability Innovation Practices in the Food Sector. Sustainability, v.7, p. 8067-8090, 2015.

BIGLIARDI, B.; GALATI, F. Models of adoption of open innovation within the food industry. Trends in Food Sciences \& Technology, v.30, p.16-26, 2013.

CHESBROUGH, H. W. Open innovation: the new imperative for creating and profiting from technology. Harvard: Harvard Business School, 2003.

COOPER, R. G. Perspective: the stage-gate (R) idea-to-launch process-update, what's new, and Nex- Gen systems. Journal of Product Innovation Management, v. 25, n. 3, p. 213-232, May 2008.

DOCHERTY, M. Primer on “Open Innovation”: principles and practice. Visions, v. 30, n. 2, p. 13-15, Apr. 2006.

EMPRESA BRASILEIRA DE PESQUISA AGROPECUÁRIA - EMBRAPA. Sustentabilidade e sustentação da produção de alimentos no Brasil: Agroindústria de alimentos. Brasília: Centro de Gestão e Estudos Estratégicos, v.4, 2014.

FOODDRINK EUROPE. Data \& trends of the European Food and Drink Industry 2013-2014. Brussels, 2014.

HUIZINGH, E. K. R. E. Open innovation: State of art and future perspectives. Technovation, v. 31, p. 2-9, 2011.

KELLEY, D. J. et al. Building an organizational capability for radical innovation: The direct managerial role. Journal of Engineering and Technology Management, v.28, n.4, p. 249-267, 2011.

LANCKER, J. V. et al. The Organizational Innovation System: A systemic framework for radical innovation at the organizational level. Technovation, v. 52-53, p. 40-50, 2016.

NAMBISAN, S.; SAWHNEY, M. Guia de compras para a feira de inovação. Tradução Walter Vasconcelos. Harvard Business Review, p. 75-83, 2007. 


\section{ANEXOS}

Práticas de inovação aberta identificadas na entrevista. Fonte: Elaborado pelos autores

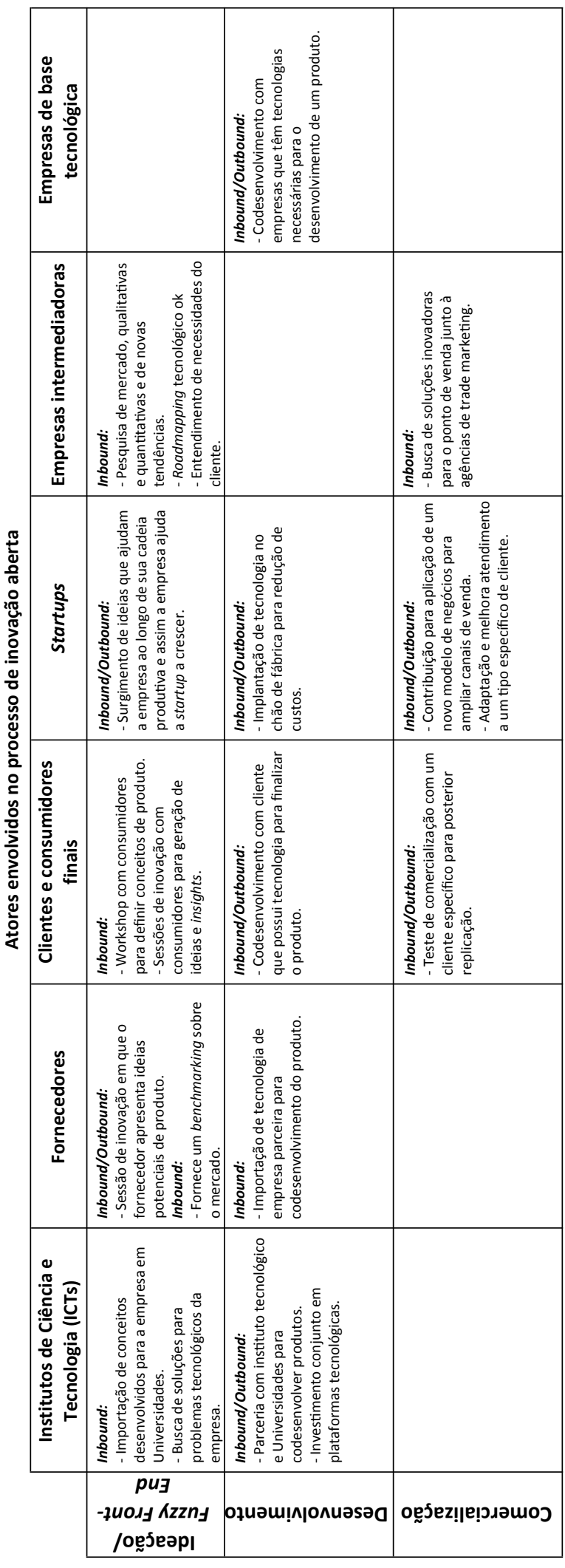

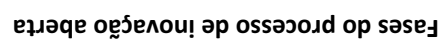

